\title{
Avaliação da exposição e risco de câncer em trabalhadores da pavimentação: um estudo baseado nos níveis de partículas respiráveis presentes nos fumos de asfalto
}

\author{
Paulo Victor Gomes Fontenele ${ }^{1}$, Verônica Teixeira Franco Castelo Branco ${ }^{2}$, \\ Rivelino Martins Cavalcante ${ }^{3}$, Wellington Lorran Gaia Ferreira ${ }^{4}$, Camille Arraes Rocha ${ }^{5}$
}

1Universidade Federal do Ceará, UFC, fontenele.paulo@hotmail.com

2Universidade Federal do Ceará, UFC, veronica@det.ufc.br

3Universidade Federal do Ceará, UFC, rivelinocaval@gmail.com

${ }^{4}$ Universidade Federal Rural do Semi-Árido, UFERSA, wellington.ferreira@ufersa.edu.br

5Universidade Federal do Ceará, UFC, camilleufc@gmail.com

\section{Recebido:}

10 de agosto de 2017

Aceito para publicação:

12 de novembro de 2017

Publicado:

31 de agosto

Editor de área:

Francisco Thiago Aragão

\section{Palavras-chaves:}

Fumos de asfalto,

Emissões;

Partícula respirável;

Exposição ocupacional

\section{Keywords:}

Asphalt fumes,

Emissions:

Respirable particle,

Occupational exposure.

DOI:10.14295/transportes.v26i2.1447

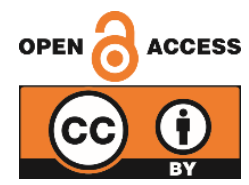

\section{RESUMO}

Serviços na área de pavimentação asfáltica são comumente empregados nos grandes centros urbanos. Recentemente, a International Agency for Research on Cancer (IARC) classificou as partículas atmosféricas externas como pertencentes ao Grupo 1, isto é, comprovadamente carcinogênicas a humanos. Desta forma, o principal objetivo deste estudo foi avaliar os níveis de Material Particulado Respirável (MPR) presentes nos fumos de asfalto, bem como o risco a saúde dos trabalhadores desse setor durante o processo de pavimentação, tanto na usinagem quanto na aplicação do material asfáltico em campo. Os resultados do estudo mostraram que na usina foram encontrados os maiores níveis de MPR, sendo os mesmos influenciados, principalmente, pela elevada produção de material. O MPR obtido durante a aplicação em campo apresentou concentrações menores e foi influenciado pela quantidade de material asfáltico utilizado na obra, a temperatura da mistura asfáltica durante a aplicação e a ventilação no local de aplicação. A exposição diária e o risco de câncer foram considerados maiores na usina se comparados aos valores encontrados em campo. Em ambos os locais, esses níveis ultrapassam os limites estabelecidos pelas principais agências que regulam a saúde ocupacional. O tipo de via urbana influenciou na distribuição dos níveis de MPR e, consequentemente, na exposição e no risco de câncer aos trabalhadores do setor.

\section{ABSTRACT}

Services in asphalt pavement are commonly employed in large urban centers. Recently, the International Agency for Research on Cancer (IARC) classified the external atmospheric particles as Group 1, i.e., proved to be carcinogenic to humans. In this way, the main objective of this study was to evaluate the levels of Respirable Particulate Material (RPM) in the asphalt fumes, as well as the health risk at the moment of the paving process, both in the plant and during the construction. The results of the study showed that the highest levels of RPM were found in the plant, being influenced mainly by the large production. The RPM obtained during the field application presented smaller concentrations and was influenced by the amount of asphalt material used, the temperature of the asphalt mixture during the application and the ventilation of the site. Daily exposure and risk of cancer were higher at the plant than in the field, and, at both places, these levels exceeded the main occupational health agencies recommendations. The type of urban road influenced in the distribution of RPM levels and, consequently, in the exposure and risk of cancer to the pavement workers. 


\section{INTRODUÇÃO}

\subsection{Fumos de Asfalto}

0 revestimento de um pavimento asfáltico é constituído basicamente pela mistura entre ligante asfáltico e agregados minerais. 0 ligante asfáltico é um material complexo e orgânico. Este deriva do refino do petróleo. Para a utilização desse material, na composição de misturas asfálticas a quente, este é aquecido a altas temperaturas, aproximadamente $160^{\circ} \mathrm{C}$. Devido ao aquecimento do ligante asfáltico, vapores são liberados e posteriormente entram em contato com a atmosfera, esfriam e, consequentemente, condensam, formando assim partículas em suspensão no ar denominadas de fumos de asfalto ou fumos de asfalto condensados (NIOSH, 2000; Gaudefroy et al., 2008).

Os compostos químicos presentes nesses fumos possuem potencial carcinogênico e variam com a origem do petróleo, o tipo de ligante asfáltico, o tempo/velocidade de usinagem e a temperatura do ambiente (NIOSH, 2000). Uma alternativa recentemente utilizada para mitigar essas emissões são as misturas asfálticas mornas. Esse tipo de mistura asfáltica consiste na utilização de tecnologias que permitem diminuir a temperatura de usinagem convencional em torno de $30^{\circ} \mathrm{C}$ a $50^{\circ} \mathrm{C}$ minimizando os danos causados pela emissão de vapores (Prowell e Hurley, 2007; Gasthauer et al., 2008). O conhecimento da composição dos fumos de asfalto ainda está em desenvolvimento, porém, estudos apontam que essa composição é constituída de substâncias orgânicas e inorgânicas, em ambos os estados, de gases e de material particulado de tamanho variado (Gaudefroy et al., 2008). A Figura 1 apresenta os fumos em uma aplicação de revestimento asfáltico e a caracterização dos mesmos a partir do estudo desenvolvido por Gaudefroy et al. (2008). COV, COT e HPA significam, respectivamente: Compostos Orgânicos Voláteis, Compostos Orgânicos Totais e Hidrocarbonetos Policíclicos Aromáticos.

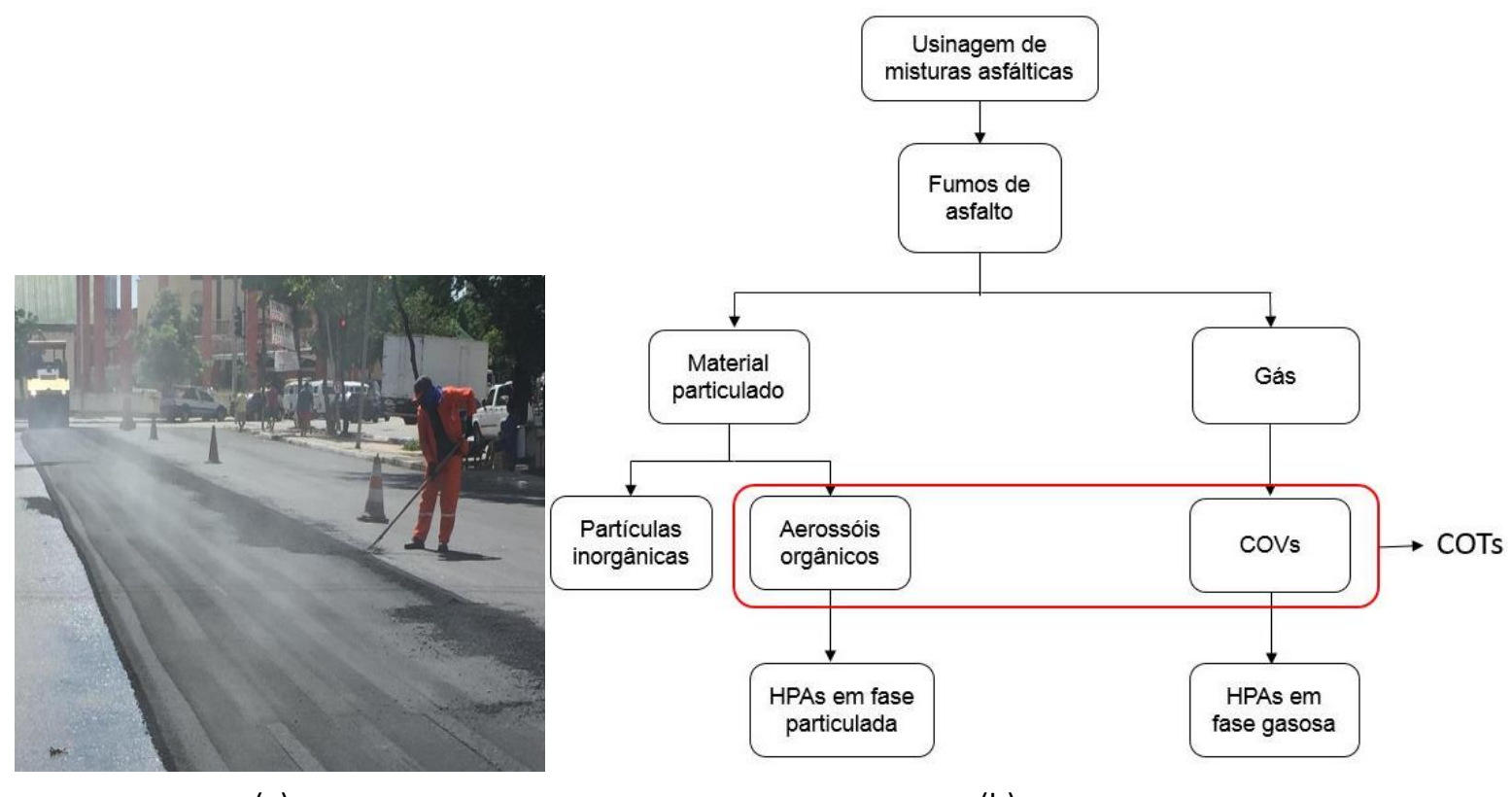

(a)

(b)

Figura 1. Presença de fumos de asfalto na aplicação de revestimento asfáltico (a) e fases presentes nos fumos de asfalto (b) (Gaudefroy et al., 2008)

\subsection{Material Particulado (MP)}

O Material Particulado (MP) é um termo genérico usado para descrever uma complexa mistura de partículas sólidas e líquidas em suspensão no ar, de origem natural ou antrópica. Sua composição é governada pelo tipo de fonte ou atividade em questão. Entre as principais fontes naturais de MP pode-se destacar as emissões de partículas do solo, do aerossol marinho e de vulcões. Partículas de origem vegetal, 
como pólens de plantas, também estão presentes na troposfera, todavia em concentrações bem menores (Seinfeld e Pandis, 1998). Já entre as fontes antropogênicas, especialmente em áreas urbanas, destacamse as emissões veiculares, atividades industriais e o uso de carvão e madeira como fontes de energia (Cavalcante et al., 2009; 2011; Guarnieri e Balmes, 2014; Silva et al., 2016). A constituição química do MP inclui íons inorgânicos (sulfatos, nitratos, amônio, sódio, potássio, cálcio, magnésio e cloreto), bem como algumas substâncias orgânicas (hidrocarbonetos de várias classes químicas) e metais (cádmio, cobre, níquel, vanádio e zinco) (Cheung et al., 2011; Cavalcante et al., 2016). Em adição, componentes biológicos (fungos e bactérias) também fazem parte da composição do MP (Rocha et al., 2017).

O MP pode ser primário, quando sua composição for de materiais emitidos diretamente na atmosfera (poeiras de diversas fontes, sais marinhos, partículas geradas mecanicamente e por combustão), ou secundário, quando são formados por vapores condensados pela reação química envolvendo precursores da fase gasosa ou de outros processos. Estas partículas, conhecidas como partículas secundárias, compõem a maior parte da poluição por partículas finas (US-EPA, 1996). 0 Material Particulado Total (MPT), ou Partículas Totais em Suspensão (PTS), é composto por partículas grossas $(2,5 \mu \mathrm{m}>\mathrm{MP} \leq 10 \mu \mathrm{m})$, bem como por partículas finas $(0,1 \mu \mathrm{m}>\mathrm{MP} \leq 2,5 \mu \mathrm{m})$ e ultrafinas $(\mathrm{MP} \leq 0,1 \mu \mathrm{m})$, denominadas, respectivamente, por $\mathrm{MP}_{10}, \mathrm{MP}_{2,5}$, e $\mathrm{MP}_{0,1}$ (US-EPA, 2016). A Figura 2a compara os tamanhos de $\mathrm{MP}_{2,5}$ e $\mathrm{MP}_{10} \mathrm{com}$ os tamanhos médios de um fio de cabelo humano $(50-70 \mu \mathrm{m})$ e grão de areia $(90 \mu \mathrm{m})$.

As partículas grossas são chamadas de inaláveis e as finas e ultrafinas são chamadas de respiráveis. As inaláveis $\left(\mathrm{MP}_{10}\right)$ são encontradas próximas à rodovias e indústrias, e são consideradas partículas menos perigosas à saúde humana pois estas são depositadas mais rapidamente. As partículas inaláveis, quando inspiradas, são retidas na parte superior do trato respiratório, isto é, na parte extratorácica, acima da laringe (Figura $2 \mathrm{~b})$. As partículas respiráveis $\left(\mathrm{MP}_{2,5}\right.$ e $\left.\mathrm{MP}_{0,1}\right)$ apresentam um maior perigo à saúde humana pois permanecem em suspensão no ar por mais tempo. Quando inspiradas podem atingir as porções mais inferiores do trato respiratório onde estão situados os alvéolos pulmonares. Os constituintes do MP podem alcançar a corrente sanguínea, se espalhando pelo corpo e chegando até as células dos organismos vivos, causando efeitos deletérios diversos (US-EPA, 2016).

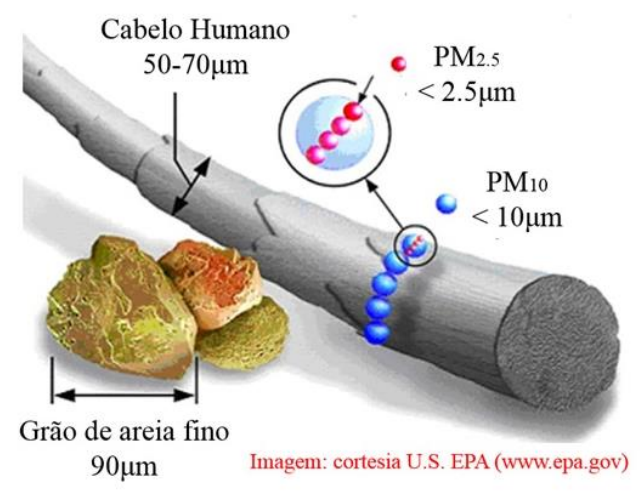

(a)

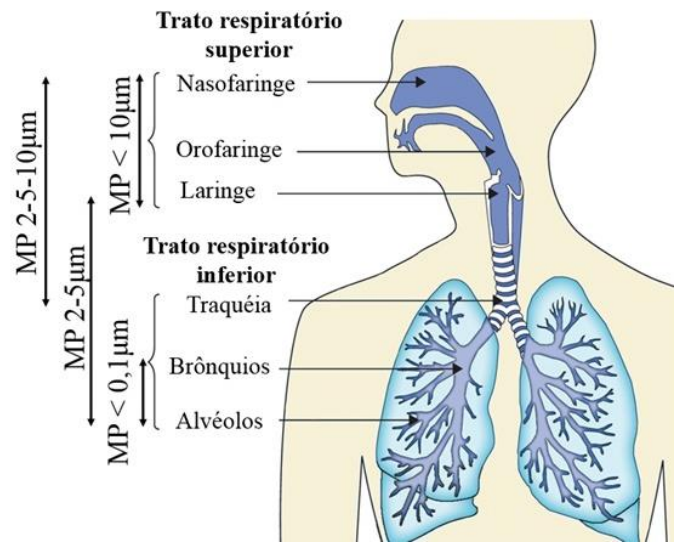

(b)

Figura 2. (a) Comparação do tamanho do $\mathrm{MP}_{2,5}$ e $\mathrm{MP}_{10}$ com fio de cabelo e grão de areia e (b) exposição por inalação e distribuição do MP entre o trato respiratório superior e inferior nos seres humanos (adaptado de Guarnieri e Balmes, 2014)

Cravo (2010) buscou comparar a exposição de trabalhadores ao MPT, proveniente dos fumos de asfalto, gerados durante a aplicação em campo de misturas asfálticas a quente e de misturas asfálticas mornas. Os resultados obtidos mostraram que todos foram expostos, em menor ou maior quantidade, ao MPT presente nos fumos de asfalto independente da função. Motta (2011) comparou os fumos de asfalto emitidos por misturas asfálticas a quente e misturas asfálticas mornas quanto aos HPAs em fase particulada. 0 citado autor analisou duas misturas asfálticas a quente (temperaturas de usinagem de 
$160^{\circ} \mathrm{C}$ e $180^{\circ} \mathrm{C}$ ) e duas misturas asfálticas mornas (temperaturas de usinagem de $135^{\circ} \mathrm{C}$ e $145^{\circ} \mathrm{C}$ ). Os resultados mostraram que a mistura usinada a $160^{\circ} \mathrm{C}$ gerou maior quantidade de HPAs se comparada as misturas asfálticas usinadas a $135^{\circ} \mathrm{C}$ e $145^{\circ} \mathrm{C}$. Gasthauer et al. (2008) também constataram que as emissões estão relacionadas com a temperatura, visto que os fumos asfálticos gerados a partir do uso de temperaturas mais elevadas, em torno de $180^{\circ} \mathrm{C}$, possuem mais chances de possuir HPAs em sua composição se comparados aos fumos gerados nas temperaturas de $160^{\circ} \mathrm{C}$ e $140^{\circ} \mathrm{C}$. Cravo et al. (2010) avaliaram 8 amostras de ligante asfáltico comercializados no Brasil. As duas variáveis relacionadas no estudo foram a temperatura que o ligante asfáltico foi aquecido em laboratório, entre $120^{\circ} \mathrm{C}$ e $180^{\circ} \mathrm{C}$, e o tempo que o ligante asfáltico foi exposto as temperaturas, entre duas e oito horas. Os autores concluíram que, para todas as amostras, a concentração de HPAs aumentou quando a temperatura e o tempo de ensaio também aumentaram.

\subsection{Exposição e Risco de Câncer aos Trabalhadores da Área de Pavimentação}

No fim da década de 80 quando foi reportada a mortalidade de trabalhadores relacionados a indústria do asfalto, foram iniciados diversos estudos relacionados a associação de casos de câncer em trabalhadores do setor de pavimentação (Hansen, 1989; Cole et al., 1999; Schreiner, 2011). Atualmente, o ligante asfáltico não é classificado como carcinogênico por agências regulatórias ou qualquer corpo científico. A IARC (International Agency for Research on Cancer) classificou recentemente esse material como pertencente ao Grupo 2B (possivelmente carcinogênico em humanos) e a ACGIH (American Conference Governmental Industrial Hygienists) classifica o mesmo como pertencente a classe A-4 (não classificado como carcinogênico a humanos devido a existência de dados inadequados) (Schreiner, 2011).

Os fumos de asfalto, a principal emissão proveniente deste material, apresenta uma composição química complexa e composta por substâncias de várias classes químicas (Binet et al., 2002; Schreiner, 2011; Zanetti et al., 2016). Apesar disso, a grande maioria dos estudos se limita a avaliar as classes de substâncias químicas presentes nos fumos reconhecidamente classificadas como carcinogênicas e mutagênicas pelas agências, especificamente os HPAs e os COVs (Schreiner, 2011; Zanetti et al., 2016). Estudos epidemiológicos a respeito de casos de câncer, levando em consideração a influência da exposição a HPAs e COVs presentes nos fumos de asfalto, são ainda inconclusivos e divergentes (Cole et al., 1999; Binet et al., 2002; Schreiner, 2011). Isso se justifica pelo fato da exposição do trabalhador aos fumos de asfalto ser múltipla e também concomitante aos fatores ligados ao seu estilo de vida fora do ambiente de trabalho (álcool e tabagismo) (Cole et al., 1999; Schreiner, 2011). Somados as divergências de resultados, estudos de controle de casos, conduzidos pela IARC, concluem que não existem evidências da associação entre indicadores de inalação ou exposição cutânea e câncer de pulmão (IARC, 2009; Olsson et al., 2010).

Alguns países instituíram um limite para a exposição aos fumos de asfalto. O Reino Unido estabelece o limite de $5 \mathrm{mg} / \mathrm{m}^{3}$ durante uma jornada de 8 h de trabalho. Já nos Estados Unidos (EU), esse mesmo valor é apenas uma recomendação. A Organização Mundial de Saúde - OMS (2006) recomenda, para uma boa qualidade do ar, concentrações inferiores a $25 \mu \mathrm{g} / \mathrm{m}^{3}$ durante $24 \mathrm{~h}$, já a Agência de Proteção Ambiental dos EU (EPA, 2010) recomenda concentrações inferiores a $35 \mu \mathrm{g} / \mathrm{m}^{3}$ durante o mesmo período. A legislação brasileira, que trata da exposição ocupacional a substâncias químicas no ar, não contempla esse poluente atmosférico. Ainda sobre a legislação brasileira, uma norma que pode enquadrar a exposição dos trabalhadores quanto aos compostos emitidos nos fumos de asfalto é a NR-15 (2008). Esta trata da exposição ocupacional a produtos químicos. A citada norma traz enquadramentos de insalubridade para trabalhadores expostos a alguns produtos químicos existentes nas emissões geradas por misturas asfálticas, por exemplo o benzeno que, em um estudo realizado por Lutes e Burnette (1994), foi encontrado em quantidade significativa em amostras de COVs coletadas em misturas asfálticas a quente. Com relação ao MP, existe a Norma de Higiene Ocupacional 08 (2009) que abrange as partículas de origem mineral, metálica, vegetal e animal, negro de fumo e partículas insolúveis não especificadas anteriormente. Esta norma classifica as partículas respiráveis, porém não enquadra os fumos de asfalto. 
Em contrapartida, estudos realizados em mais de 30 países revelaram que a cada aumento de $10 \mu \mathrm{g} / \mathrm{m}^{3}$ nos níveis de $\mathrm{MP}_{2,5}$, houve um acréscimo na taxa de câncer de pulmão entre 9 e $36 \%$ nos últimos anos (Raaschou-Nielsen et al., 2013; Hamra et al., 2014). Nesse sentido, recentemente, a IARC classificou as partículas atmosféricas externas - material particulado em suspensão no ar de ambientes externos/abertos - como pertencentes ao Grupo 1 (carcinogênicos a humanos) devido ao fato das mesmas alcançarem os alvéolos pulmonares e a corrente sanguínea, causando mutagênese permanente, ataques cardíacos, doenças relacionadas a alteração na pressão arterial e até a morte prematura (Hamra et al., 2014). Essa reclassificação pela IARC foi um avanço para tornar o monitoramento do MP prioritário, com possibilidade de expansão por agências ligadas à saúde ocupacional de trabalhadores expostos a essa classe de contaminante.

O principal objetivo deste trabalho foi avaliar os níveis de Material Particulado Respirável (MPR) presente nos fumos de asfalto emitidos durante os serviços de usinagem e aplicação de misturas asfálticas a quente. Devido à escassez de estudos relacionados aos trabalhadores da pavimentação, foram avaliados os riscos à saúde dessa classe considerando a recente classificação da IARC quanto aos riscos de câncer provenientes da exposição ao MP. 0 presente estudo contribuirá para a discussão referente a saúde ocupacional, bem como para a elaboração de políticas públicas relacionadas ao setor da pavimentação.

\section{MATERIAIS E MÉTODOS}

\subsection{Coleta Do Material Particulado Respirável (MPR)}

Os materiais e equipamentos utilizados na pesquisa, bem como uma vista completa do equipamento montado para realizar a coleta do MPR $(\leq 2,5 \mu \mathrm{m})$ são apresentados na Figura 3.

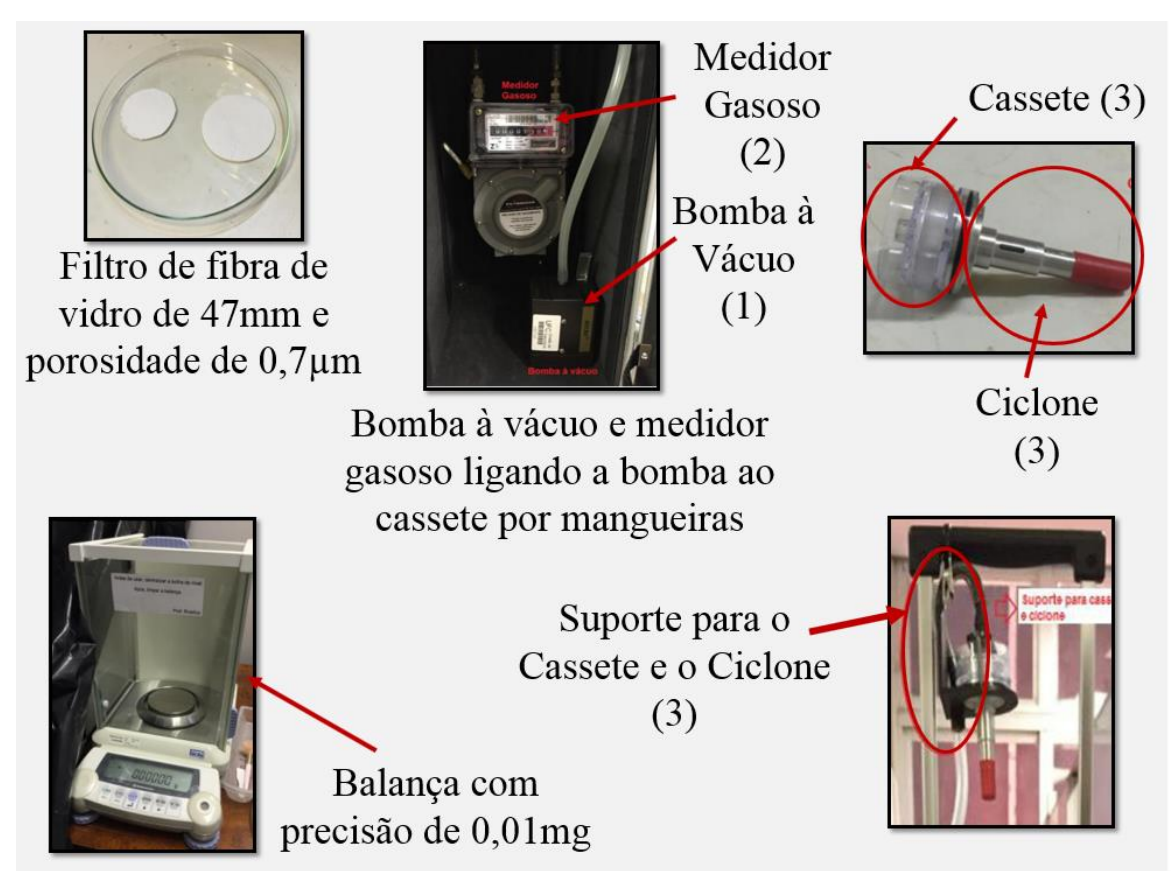

(a)

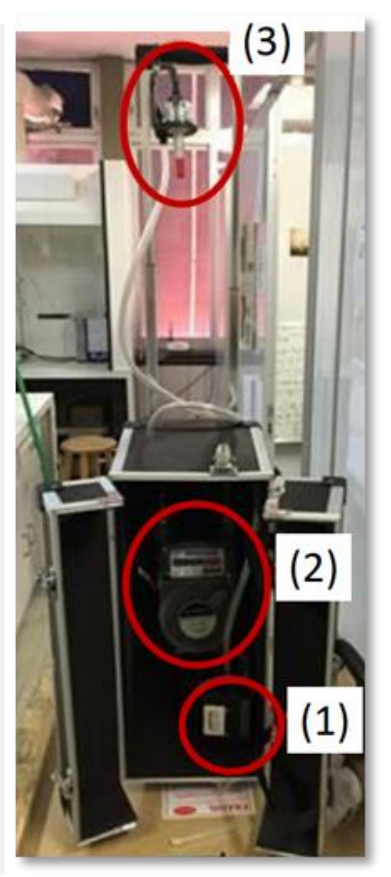

(b)

Figura 3. Detalhamento dos dispositivos e materiais utilizados para coletar MPR (a) e vista do equipamento montado (b)

Para a coleta do MPR utilizou-se um sistema (Figura 3) montado em laboratório especialmente para este tipo de estudo. 0 equipamento portátil em questão é um amostrador ativo (que utiliza uma força externa e artificial que suga o ar para dentro do sistema) montado seguindo os mesmos padrões dos equipamentos existentes no mercado. Existem inúmeros amostradores ativos e analisadores automáti- 
cos para a coleta de poluentes atmosféricos disponíveis, porém optou-se por montar um sistema semelhante em laboratório porque este é de baixo custo e oferece maior controle e exatidão com relação aos dados obtidos.

Os filtros de fibra de vidro utilizados nas análises foram colocados na estufa a $100^{\circ} \mathrm{C}$ durante $48 \mathrm{~h}$, com intuito de retirar toda a umidade presente nos mesmos. Após esse período, o filtro é colocado no dessecador durante uma hora para que o mesmo possa esfriar sem receber umidade. Em seguida, os filtros foram pesados na balança de precisão, onde o peso considerado para a posterior realização das análises é a média dos cinco pesos encontrados. Dessa maneira, é possível obter o peso do filtro antes da amostragem. Para a coleta do MPR foi utilizada a configuração mostrada na Figura 3b. Através da bomba de amostragem com vazão em torno de $3 \mathrm{~L} / \mathrm{min}$, a amostra de ar é coletada, esta entra através do ciclone onde as partículas acima de $10 \mu \mathrm{m}$ presentes na amostra de ar batem na parede do ciclone e caem em um recipiente de coleta. Já as partículas respiráveis, que possuem tamanho menor do que $10 \mu \mathrm{m}$, sobem e ficam retidas no filtro de fibra de vidro. 0 medidor gasoso retorna o valor total de ar coletado pela bomba em $\mathrm{m}^{3}$.

A coleta foi realizada tanto na usina quanto no campo. A Figura 4a apresenta a usina na qual foram feitas as coletas. Essa usina é do tipo móvel e possui capacidade de produção de até 160 ton/h, 4 dosadores para agregados com capacidade de $6 \mathrm{~m}^{3}$ cada, secador do tipo contra fluxo, elevador de massa, cabine de comando e sistema de controle de pesagem dos agregados. 0 local escolhido para a coleta foi próximo a saída do misturador e do elevador de mistura asfáltica, Figura 4b. 0 local da coleta foi escolhido de maneira tal que a amostra de ar colhida deveria conter a maior quantidade de fumos de asfalto possível.

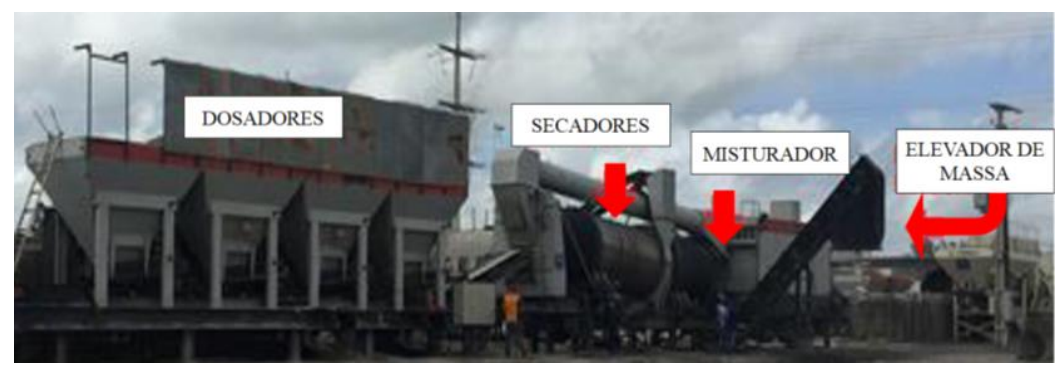

(a)

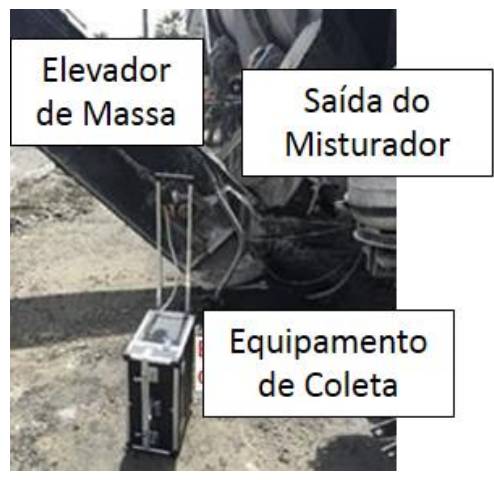

(b)

Figura 4. Usina utilizada para a realização das coletas (a) e ponto de coleta (b)

Foram realizadas duas coletas. A primeira coleta foi realizada no período entre 10:00h e 14:00h, o céu estava nublado com temperatura aproximada de $26^{\circ} \mathrm{C}$ e umidade de $80 \%$. Durante a coleta, a produção da usina era de 145 ton/h de Concreto Asfáltico (CA) com temperatura de usinagem de $150^{\circ} \mathrm{C}$ e teor de Cimento Asfáltico de Petróleo (CAP) de 5,3\%. Já a segunda coleta foi realizada entre 8:00h e 11:00h, o céu estava nublado com temperatura de $27^{\circ} \mathrm{C}$ e umidade de $76 \%$. Nessa segunda coleta, a produção da usina era de $85 \mathrm{ton} / \mathrm{h}$, e a mistura asfáltica foi dosada para 5,8\% de CAP e temperatura de usinagem de $150^{\circ} \mathrm{C}$.

Além da coleta realizada na usina, foram coletados dados na aplicação da mistura asfáltica em campo em dois locais diferentes. A primeira coleta (Campo 1) foi realizada durante uma obra de recapeamento na avenida Bezerra de Menezes em Fortaleza, CE. A Figura 5 (a e b) apresenta a vibroacabadora utilizada para aplicar a mistura asfáltica, bem como o ponto onde foi realizada a coleta. A coleta foi realizada entre 9:00h e 17:00h. 0 céu tinha poucas nuvens e a temperatura era de $30^{\circ} \mathrm{C}$ com umidade próxima de $70 \%$. A coleta teve duração de $5 \mathrm{~h}$ e, durante a amostragem, o equipamento ficou o mais próximo possível da vibroacabadora, para que os fumos de asfalto fossem coletados antes que os mesmos se dispersassem. 
A mistura asfáltica aplicada na obra era do tipo CA com teor de CAP de 5,2\%. Além da coleta de MPR, foi recolhida uma amostra do material utilizado na obra para verificação da \% de CAP em laboratório.

A segunda coleta (Campo 2) foi realizada durante uma obra na rua Alberto Magno em Fortaleza, CE, 23:00 e 03:00h. A Figura 5 (c e d) apresenta a obra sendo acompanhada. 0 céu estava com poucas nuvens e não havia chovido durante o dia, a temperatura era de aproximadamente $28^{\circ} \mathrm{C}$ e a umidade de $50 \% .0$ equipamento ficou, durante toda a coleta, também próximo a vibroacabadora. A mistura asfáltica aplicada na obra era do tipo CA com teor de CAP de 5,3\%.

Após a realização das amostragens na usina e em campo, os filtros contendo o MPR receberam o mesmo tratamento na estufa e no dessecador seguido da pesagem a partir do uso da balança de precisão, obtendo-se assim o peso do filtro coletado. Para obter a concentração de MPR contida na amostra de ar, a Equação 1 foi utilizada.

$$
\mathrm{C}_{\mathrm{MPR}}=\frac{\mathrm{P}_{\mathrm{Fd}}-\mathrm{P}_{\mathrm{Fa}}}{\mathrm{Q}_{\mathrm{ar}}}
$$

em que: $C_{M P R}$ : Concentração do material particulado respirável $\left(\mu \mathrm{g} / \mathrm{m}^{3}\right)$;

$\mathrm{P}_{\mathrm{Fd}}$ : Peso do filtro depois da amostragem $(\mu \mathrm{g})$;

$P_{\text {Fa: }}$ Peso do filtro antes da amostragem $(\mu \mathrm{g})$;

Qar: Quantidade de ar que passou pelo filtro $\left(\mathrm{m}^{3}\right)$.

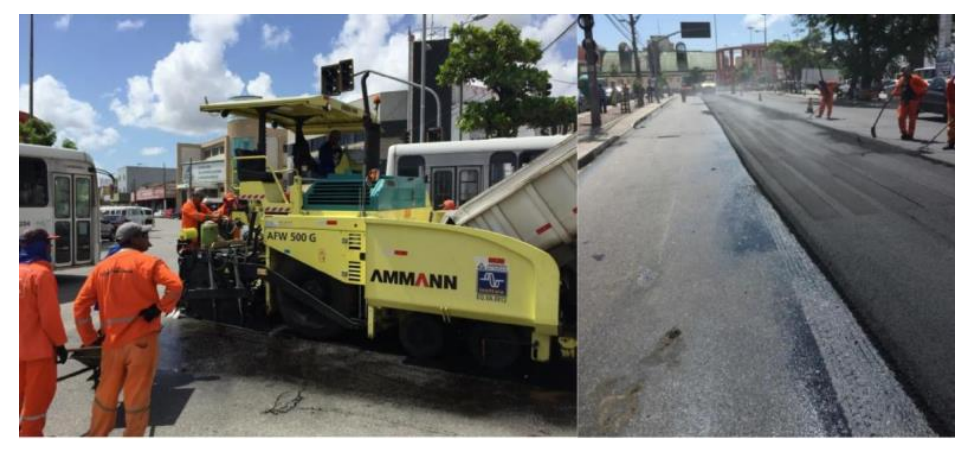

(a)

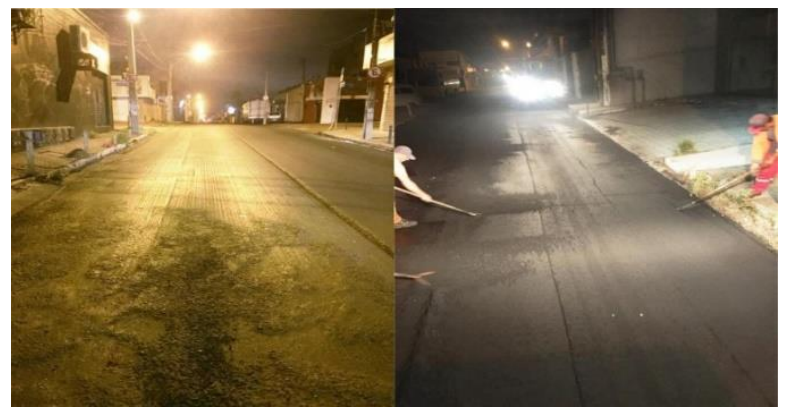

(c)

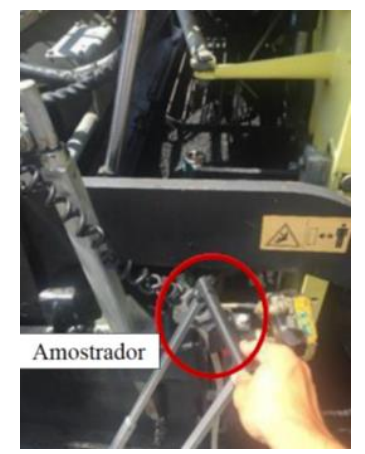

(b)

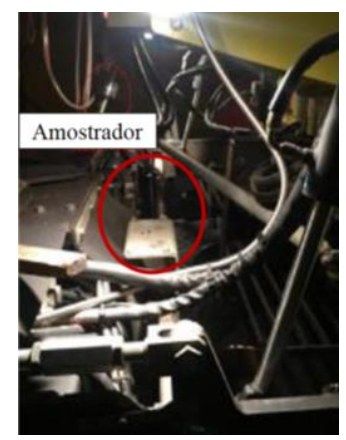

(d)

Figura 5: Coleta de MPR realizada no Campo 1 - avenida Bezerra de Menezes (a e b) e coleta de MPR realizado no Campo 2 - rua Alberto Magno (c e d)

\subsection{Avaliação do Risco à Saúde ao Material Particulado Respirável (MPR)}

O risco à saúde ao MPR foi estimado baseado na Exposição Diária (ED) e no Risco de Câncer (RC) dos trabalhadores dentro da usina e no momento da aplicação em campo. 0 cálculo da Exposição Diária (ED) ( $\mu \mathrm{g} / \mathrm{d})$ (US-EPA,1992) é expresso pela Equação 2.

$$
\mathrm{ED}=\mathrm{C}_{\mathrm{MPR}} \times \mathrm{RI} \times \mathrm{T}
$$

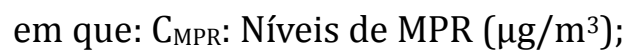


RI: Razão de Inalação $\left(\mathrm{m}^{3} / \mathrm{h}\right)$;

T: Tempo de exposição $(\mathrm{h} / \mathrm{d})$.

Estima-se que uma pessoa (adulta não asmática), em suas atividades normais, apresenta uma RI de 0,72 a $1,02 \mathrm{~m}^{3} \mathrm{de}$ ar por hora $\left(\mathrm{m}^{3} / \mathrm{h}\right)$ (baixa a média inalação), enquanto que uma pessoa exercendo suas funções de forma rápida apresenta RI de $3,06 \mathrm{~m}^{3} / \mathrm{h}$ (alta inalação) (US-EPA, 1997). Para este estudo, a RI utilizada para os trabalhadores da usina foi de $1,02 \mathrm{~m}^{3} / \mathrm{h}$ e para os trabalhadores em atividade de campo foi de $3,06 \mathrm{~m}^{3} / \mathrm{h}$. Para o cálculo do risco de câncer foi feito primeiramente o cálculo da Ingestão Crônica Diária (do inglês, cronic daily intake - CDI) (US-EPA, 1992, 1996, 1997), que pode ser expresso pela Equação 3, assumindo os valores apresentados na Tabela 1.0 cálculo do RC pode ser expresso pela Equação 4.

$$
\begin{gathered}
\mathrm{CDI}=\frac{(\mathrm{CA} \times \mathrm{RI} \times \mathrm{ED} \times \mathrm{EF} \times \mathrm{L})}{(\mathrm{BW} \times \mathrm{ATL} \times \mathrm{NY})} \\
\mathrm{RC}=\mathrm{CDI} \times \mathrm{RR}
\end{gathered}
$$

em que: CDI: Ingestão Crônica Diária;

RR: Risco Relativo, valores estimados encontrados pelo estudo de Hamra et al. (2014).

Tabela 1: Descrição das variáveis usadas no cálculo da exposição e ingestão crônica diária

\begin{tabular}{cccc}
\hline Parâmetro & Descrição & Valor & Unidade \\
\hline CA & Concentração do contaminante & - & $\mathrm{mg}^{-3}$ \\
RI & Taxa de inalação (adulto) & $1,02 / 3,06$ & $\mathrm{~m}^{-3} \mathrm{~h}^{-1}$ \\
ED & Duração da exposição (adulto) & 40 & $\mathrm{~h}^{-1}$ semana $^{-1}$ \\
EF & Frequência de exposição & 48 & semana $^{-1}$ ano $^{-1}$ \\
L & Tempo de exposição & $35^{\mathrm{a}}$ & ano \\
BW & Peso corporal homem & $70^{\mathrm{b}}$ & $\mathrm{kg}$ \\
ATL & Expectativa de vida do homem & $72^{\mathrm{b}}$ & ano \\
NY & Número de dias do ano & 365 & $\mathrm{~d}^{-1} \mathrm{ano}^{-1}$
\end{tabular}

${ }^{a}$ Considerando um cenário de uma pessoa com vida ocupacional ativa de 35 anos. ${ }^{\mathrm{b}}$ IBGE (2016)

\section{RESULTADOS E DISCUSSÕES}

\subsection{Níveis de Material Particulado Respirável (MPR)}

Na primeira coleta realizada na usina (Usina C.1) foi obtida uma concentração de $780 \mu \mathrm{g} / \mathrm{m}^{3}$ $\left(195 \mu \mathrm{g} / \mathrm{m}^{3} / \mathrm{h}\right)$ de MPR, já na segunda coleta (Usina C.2) a concentração de MPR foi de $530 \mu \mathrm{g} / \mathrm{m}^{3}$ $\left(176,7 \mu \mathrm{g} / \mathrm{m}^{3} / \mathrm{h}\right)$, Figura 6. Quanto as coletas em campo obtidas durante a aplicação da mistura asfáltica, no Campo 1 (Av. Bezerra de Menezes), a concentração de MPR foi de $23 \mu \mathrm{g} / \mathrm{m}^{3}\left(4,6 \mu \mathrm{g} / \mathrm{m}^{3} / \mathrm{h}\right.$ ), enquanto que no Campo 2 (Rua Alberto Magno) foi de $162 \mu \mathrm{g} / \mathrm{m}^{3}\left(32,4 \mu \mathrm{g} / \mathrm{m}^{3} / \mathrm{h}\right.$ ). Na Figura 6 também é possível observar os limites máximos estabelecidos pela OMS (2006) $\left(25 \mu \mathrm{g} / \mathrm{m}^{3}-1,04 \mu \mathrm{g} / \mathrm{m}^{3} / \mathrm{h}\right)$ e pela US-EPA (2010) $\left(35 \mu \mathrm{g} / \mathrm{m}^{3}-1,46 \mu \mathrm{g} / \mathrm{m}^{3} / \mathrm{h}\right)$.

É possível observar que todas as concentrações obtidas nas coletas ficaram acima do limite máximo (para a coleta realizada na usina quase 200 vezes maior, já para a coleta realizada em campo pode chegar a 30 vezes maior), determinado como seguro à saúde humana, pela OMS e pela US-EPA, principalmente nas coletas realizadas dentro da usina. 0 local onde foram coletados os fumos de asfalto na usina não possuía uma grande movimentação de trabalhadores, geralmente, apenas um trabalhador se aproxima 
do local, muitas vezes sem a máscara protetora.

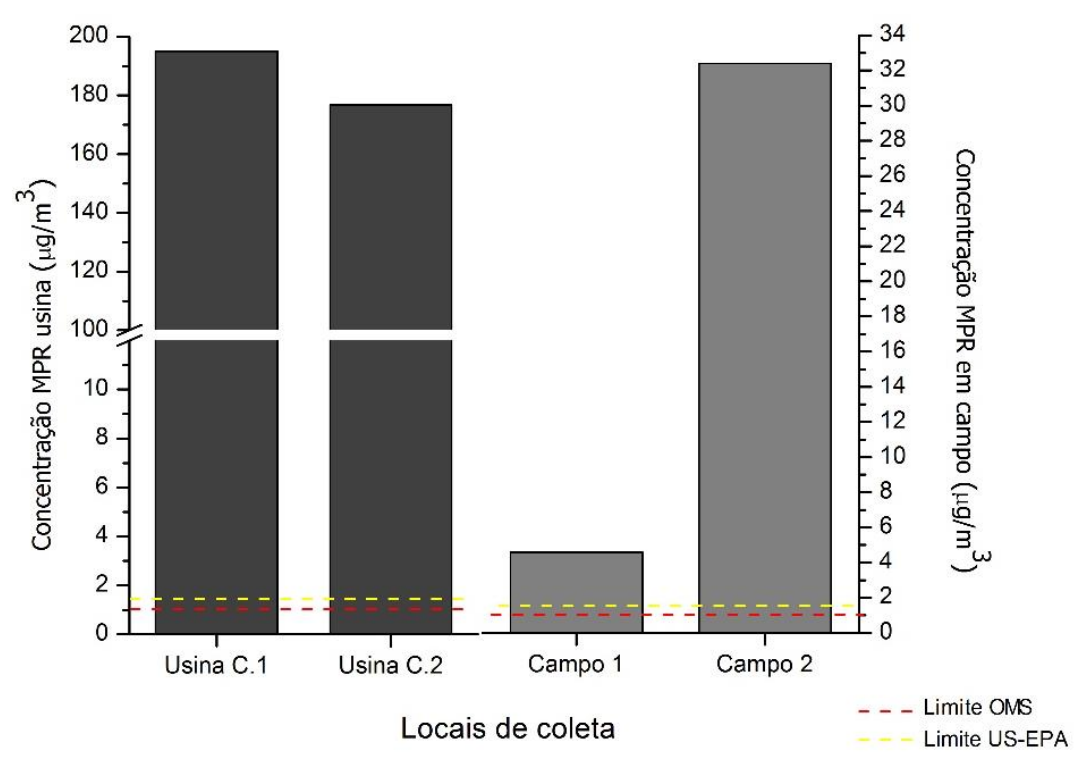

Figura 6. Valores de MPR medidos na usina e em campo

Com relação à diferença encontrada nos valores nas duas coletas na usina (redução no valor de MPR de aproximadamente 10\%), alguns fatores podem ter contribuído com este resultado. Na primeira coleta (maior valor de MPR observado), a usina estava trabalhando com uma produção de 145 ton/h enquanto que na segunda coleta, a produção era de 85 ton/h, redução de cerca de $41 \%$. Quanto a mistura asfáltica que estava sendo produzida, na primeira coleta foi usinada uma mistura do tipo CA com 5,3\% de CAP, enquanto que na segunda coleta foi produzida uma mistura asfáltica para atividades de "tapa buraco" com 5,8\% de CAP. Desta forma, essa maior porcentagem de CAP, 0,5\%, presente na segunda mistura, não foi suficiente para reduzir essa diferença entre as concentrações dos materiais particulados nas duas coletas.

É possível observar que houve diferença nos níveis de MPR encontrados nas coletas em campo, cuja concentração obtida no Campo 2 foi 7 vezes maior que a concentração medida no Campo 1. Este resultado pode estar ligado ao fato de que na coleta realizada durante a obra do Campo 1 foram aplicadas 339 toneladas de mistura asfáltica, enquanto que na obra do Campo 2 foram aplicadas 474 toneladas. Além disso, o tempo utilizado para a aplicação da mistura asfáltica foi de 7,5h e 4 h para as obras do Campo 1 e 2, respectivamente. Essa diferença de tempo é explicada pelo fato da obra do Campo 1 ter sido realizada durante o dia, em uma avenida movimentada, o que dificulta o deslocamento dos caminhões-caçamba da usina em direção ao trecho. Já na obra do Campo 2, realizada durante a madrugada, onde praticamente não existe tráfego, a aplicação ocorreu de maneira mais rápida. As diferenças de distância entre a usina e os trechos avaliados estão na Figura 7. Essa diferença de tempo impacta, principalmente, na temperatura na qual a mistura asfáltica é aplicada em campo, pois quanto maior o tempo gasto no trajeto, maior deve ser o calor perdido da mistura asfáltica para o ambiente. Tal fato reduz a quantidade de fumos de asfalto liberados durante a aplicação do material asfáltico, como foi identificado por Cravo (2010).

No estudo realizado por Cravo (2010), o MPT para misturas asfálticas a quente, foi, em média, $830 \mu \mathrm{g} / \mathrm{m}^{3}$. O Instituto Nacional de Segurança e Saúde Ocupacional dos EUA (NIOSH) (2000) também realizou um estudo em 7 obras em várias regiões dos EU, onde foram encontradas concentrações médias de MPT de $454 \mu \mathrm{g} / \mathrm{m}^{3}$. Rocha (2014) coletou MPR, proveniente principalmente do fluxo de veículos, em 3 praças da cidade de Fortaleza e encontrou uma concentração média de $80 \mu \mathrm{g} / \mathrm{m}^{3}$. Hicks (1995) coletou MP proveniente de 6 usinas de misturas asfálticas nos EUA e encontrou uma concentração de $780 \mu \mathrm{g} / \mathrm{m}^{3}$, mesmo resultado encontrado neste estudo. Vale ressaltar que, nos três primeiros estudos citados acima foram coletados MPT, justificando a alta concentração de MP encontradas, diferente do estudo de Rocha 
(2014), que coletou somente MPR e encontrou níveis inferiores, tal como os estudos de Rocha et al. (2017) e Silva et al. (2016) que também coletaram MPR e com resultados que possuem a mesma ordem de magnitude daqueles encontrados no presente estudo.

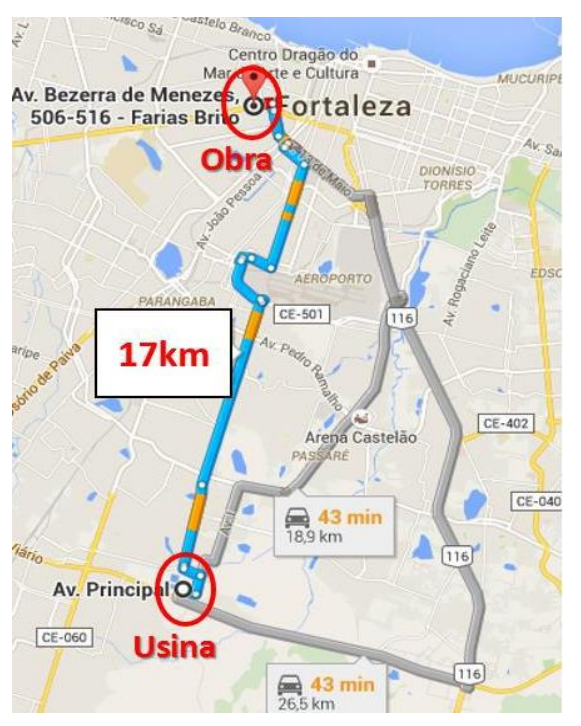

(a)

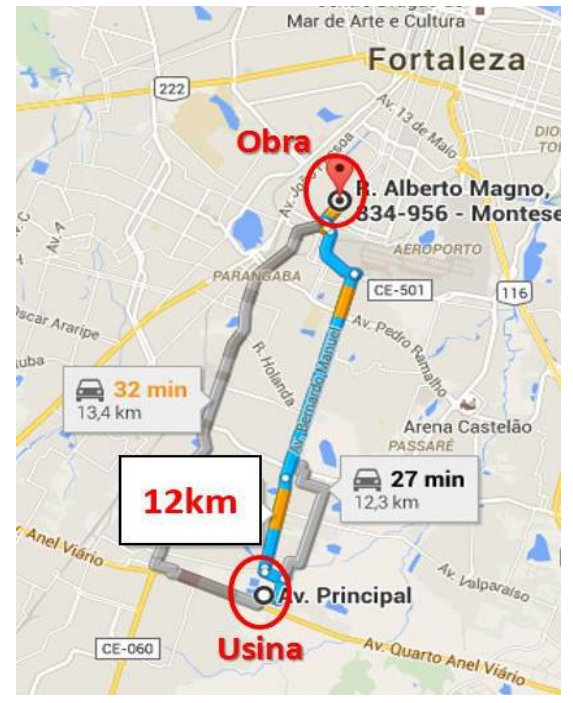

(b)

Figura 7. Distâncias dos trajetos entre a usina e os trechos avaliados em campo, Campo 1 - Av. Bezerra de Menezes (a) e Campo 2 - Rua Alberto Magno (b)

Outro fator que pode ter afetado a concentração de MPR, no presente estudo, foi a dispersão ocorrida em campo. 0 Campo 1, por ser uma via de pista dupla (Figura 8a), cada uma com três faixas de rolamento, possui uma caixa da via maior se comparada ao Campo 2, Figura 8b, que possui apenas uma pista com duas faixas de rolamento. Dessa maneira, a coleta realizada no Campo 1 foi mais exposta a ação dos ventos, o que deve ter ocasionado uma maior velocidade na dispersão dos fumos de asfalto emitidos durante a aplicação do material asfáltico. A razão H/W (H = Height (altura) e W= Width (largura)) é governante na dispersão de calor, bem como de poluentes em cidades com altos índices de edificações (Oke, 1988). A razão H/W no Campo 2 é quatro vezes superior àquela encontrada no Campo 1 , sendo outra evidência que justifica os resultados encontrados. Altas razões de H/W são responsáveis pela mudança na direção e diminuição na velocidade dos ventos e, consequentemente, pela alteração na qualidade ambiental em centros urbanos com intenso processo de verticalização (Cavalcante et al., 2016; Silva, 2016; Aguiar et al., 2017; Rocha et al., 2017).
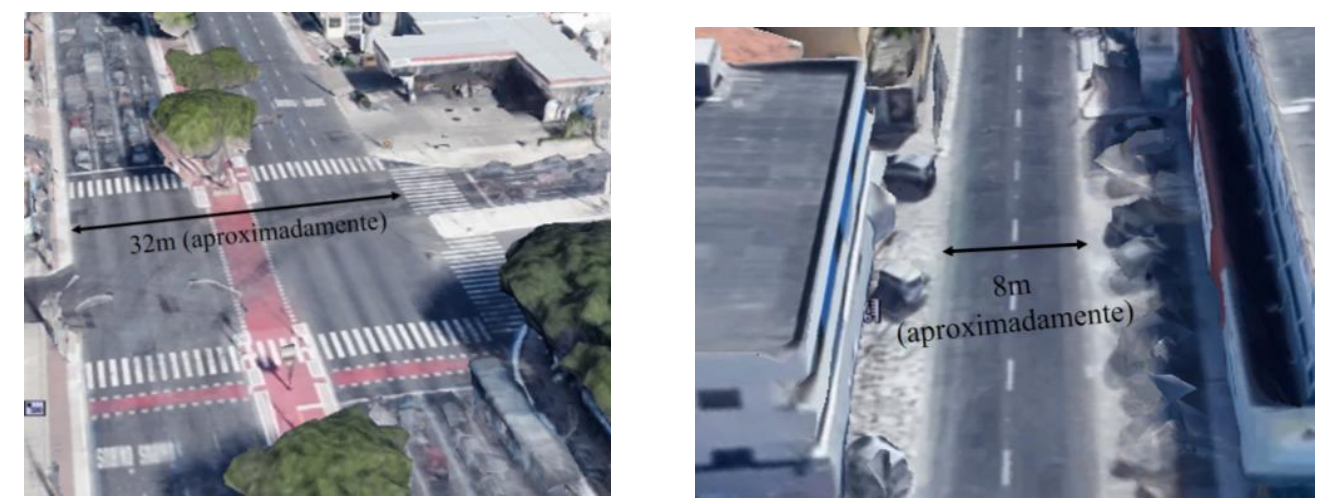

Figura 8. Diferença nos tamanhos das caixas das vias avaliadas em campo, Campo 1 - Av. Bezerra de Menezes (a) e Campo 2 - Rua Alberto Magno (b)

Segundo o relatório fornecido pela empresa produtora da massa asfáltica, o teor de CAP utilizado na obra do Campo 1 foi de 5,2\%. Na verificação feita em laboratório o valor chegou a 5,1\%, praticamente o 
mesmo valor de projeto. Enquanto que a porcentagem de CAP utilizada no Campo 2 foi de 5,3\%. Essas diferenças são mínimas, portanto, não é possível afirmar que a porcentagem de CAP encontrada no material aplicado no Campo 2 favoreceu a emissão de material particulado se comparado a porcentagem de CAP utilizada no Campo 1.

\subsection{Risco à Saúde dos Trabalhadores}

\subsubsection{Exposição diária ao Material Particulado Respirável (MPR)}

Para o cálculo da Exposição Diária (ED) dos trabalhadores da usina, uma média dos dois níveis encontrados foi obtida para reportar a exposição referente à usina, assim, a exposição obtida na usina $(1516,4 \mu \mathrm{g} / \mathrm{d})$ foi a maior verificada no estudo, Figura 9. Entre os resultados obtidos para os trabalhadores em campo, a maior ED foi encontrada no Campo $2(793,2 \mu \mathrm{g} / \mathrm{d})$, aproximadamente 8 vezes maior que a exposição encontrada no Campo $1(112,6 \mu \mathrm{g} / \mathrm{d})$. Na Figura 9 é possível observar os limites máximos de

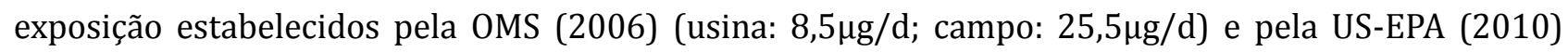
(usina: $12 \mu \mathrm{g} / \mathrm{d}$; campo: $35,7 \mu \mathrm{g} / \mathrm{d}$ ).

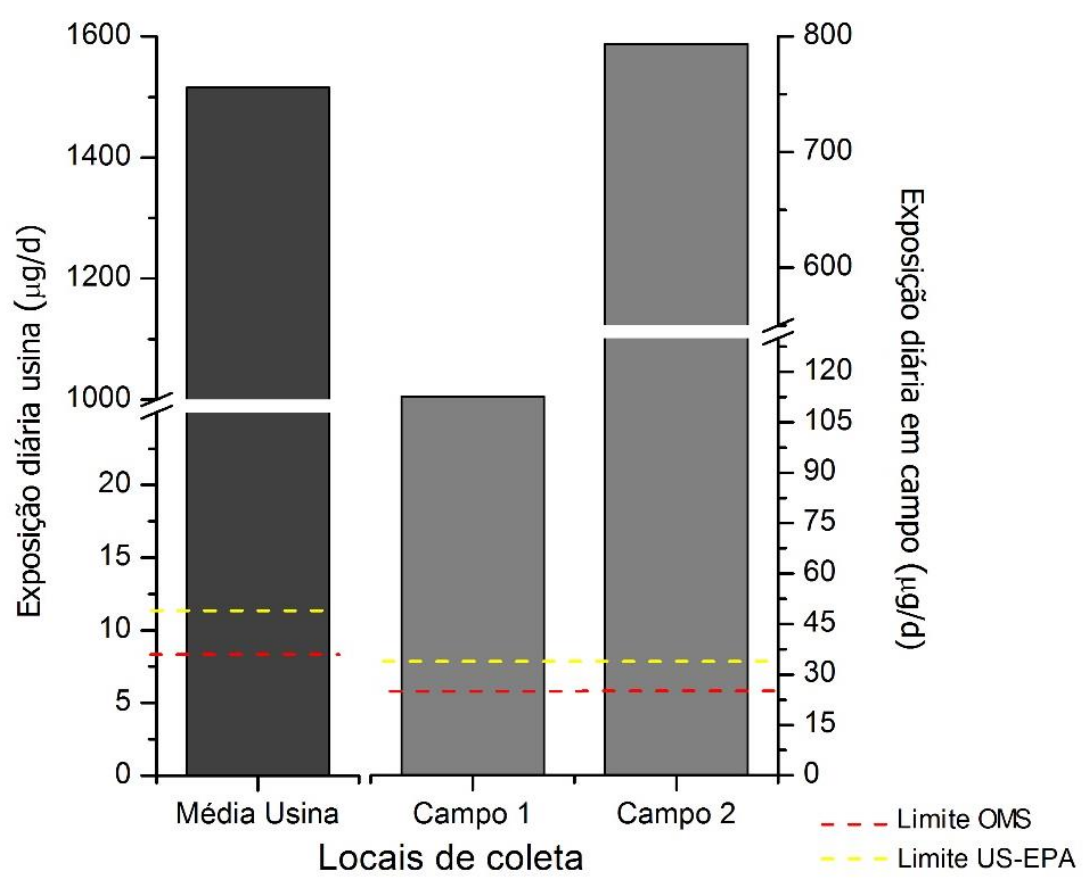

Figura 9. Exposição Diária (ED) dos trabalhadores ao Material Particulado Respirável (MPR) na usina e nos dois pontos observados em campo

Para os três locais coletados (Figura 9), os limites estabelecidos pelas agências de proteção foram extrapolados. Na usina, o valor de ED é cerca de 178 vezes maior que o limite máximo recomendado pela OMS e 126 vezes maior que o limite estabelecido pela US-EPA. Enquanto que no campo essa extrapolação vai de 3 a 31 vezes maior que os limites recomendados pelas duas agências. Na usina essa exposição pode estar sendo superestimada, pois as concentrações de MPR obtidas se encontram numa área de pouco movimento de funcionários. Para se obter um valor de ED mais realista seria necessária uma análise do tempo aproximado de exposição que os funcionários realmente têm no local estudado. Já em campo, apesar do valor de RI ser maior que o valor considerado para a usina, a concentração de MPR em campo foi menor, como já comentado anteriormente.

\subsection{Risco de Câncer (RC)}

A estimativa do RC foi avaliada usando a equação de CDI e o Integrated Risk Information System (IRIS) 
foi baseado em 35 anos de exposição ocupacional aos níveis de MPR para homens. O RC foi estimado através da CDI multiplicada pelo Risco Relativo (RR), de acordo com a US-EPA $(1992,1996)$ e com o estudo conduzido por Hamra et al. (2014). Esses autores analisaram a relação "casos de câncer de pulmão e níveis de partículas em suspensão na atmosfera em centros urbanos", o que gerou valores (adimensionais) estimados por meio de análise estatística que representam o risco de incidência/mortalidade por câncer de pulmão associado ao MPR de 2,5 $\mu \mathrm{m}$. Para o presente estudo foi utilizado o risco relativo ao MPR para todos os tipos de trabalhadores (1,09 - risco geral), para os que fumam há muitos anos (1,44 - fumantes antigos) e para os que nunca fumaram (1,18 - nunca fumantes). A estimativa do $\mathrm{RC}$ para os trabalhadores na usina e no campo pode ser observada na Figura 10. É possível perceber que o RC para trabalhadores que fumam há muito tempo é maior que o RC para trabalhadores que nunca fumaram, nos diferentes locais de coleta. Quando se compara o RC dos trabalhadores da usina com os valores encontrados em campo essa diferença se torna muito significativa, sendo o RC da usina (considerando somente o risco geral) 13,5 vezes maior que o RC do Campo 1 e 1,9 vezes maior que o RC encontrado para o Campo 2.

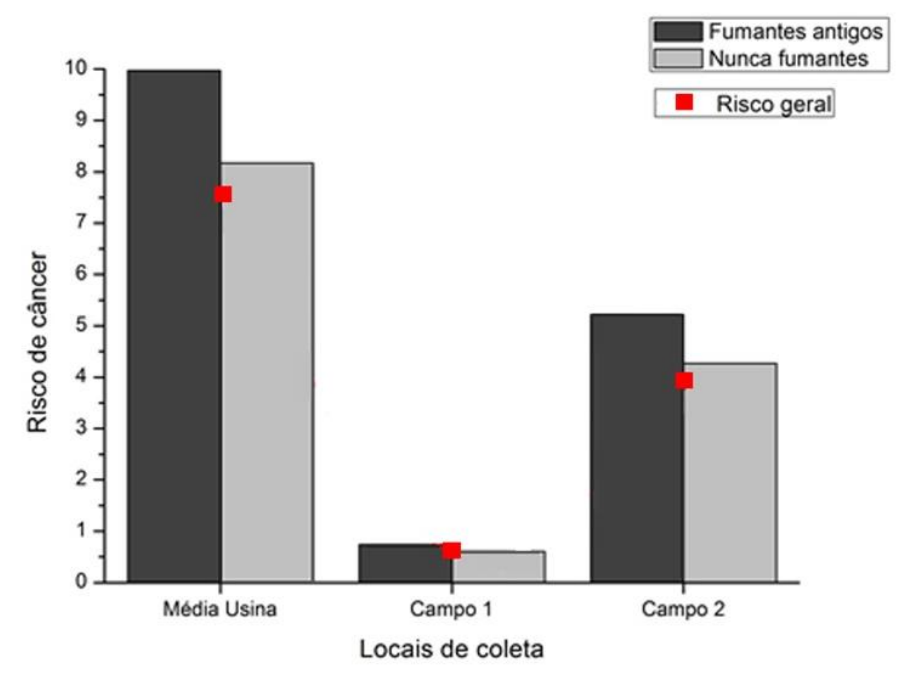

Figura 10. Risco de Câncer (RC) dos trabalhadores ao Material Particulado Respirável (MPR) na usina e em campo

Um elevado risco à saúde destes tipos de trabalhadores também foi encontrado pelos estudos de Partanen e Boffetta (1994) e McClean et al. (2004), que avaliaram o risco de câncer em trabalhadores do setor de pavimentação asfáltica a alguns poluentes orgânicos emitidos durante esta atividade, como os HPAs, bem como o nível de exposição destas pessoas através das vias inalatórias e dérmicas.

As agências regulatórias, OMS e US-EPA, também estabelecem um limite de concentração de MPR na atmosfera para não oferecer risco de câncer às pessoas expostas a um determinado ambiente. Para esse estudo, os limites estabelecidos pelas agências foram calculados com as variáveis utilizadas para calcular o RC dos locais de coleta, entretanto, esses valores não foram expressos no gráfico por serem de escala muito reduzida, cujos valores variaram somente de 0,05 a 0,23 , enquanto que o RC da usina e dos dois locais avaliados em campo variaram de 0,61 a 10,00. A estimativa do RC calculada neste estudo revela que todos os locais de trabalho analisados oferecem RC a seus trabalhadores, pois estas estimativas ultrapassaram os limites máximos permitidos pelas agências regulatórias de saúde e meio ambiente, sendo que a usina oferece um risco à saúde dos seus trabalhadores bem maior que os dois pontos avaliados em campo. Como a IARC reclassificou o MP como carcinogênico recentemente, infelizmente, não 
foram encontrados na literatura estudos para a comparação e discussão dos resultados obtidos no presente estudo.

\section{CONCLUSÕES}

Recentemente, a IARC reclassificou as partículas atmosféricas externas como carcinogênicas a humanos. Dessa forma, os níveis de MPR no fumo de asfalto, emitidos em serviços de pavimentação, bem como seu risco à saúde, foram avaliados. No presente trabalho, o nível de exposição e o RC aos trabalhadores do setor de pavimentação foram avaliados em duas condições distintas: i) durante a produção de mistura asfáltica em usina e ii) durante a aplicação do material em campo, considerando diferentes condições de tráfego, de distância ao local de aplicação (o que impacta na temperatura do material) e da geometria da via (número de faixas de tráfego).

Os níveis de MPR foram governados pela quantidade de mistura asfáltica para as amostras coletadas em usina e pelo tipo de via urbana para as amostras coletadas em campo, uma vez que foi observado correlação indireta entre a geometria da via e os níveis de MPR. A exposição diária ao MPR foi maior na usina do que no campo, e esses níveis ultrapassaram os limites estabelecidos pelas agências ligadas a saúde ocupacional de trabalhadores. A quantidade de mistura asfáltica produzida foi fator determinante na observação do nível de exposição e no RC. Para as amostras avaliadas em campo, uma diferença da ordem de $0,5 \%$ de CAP para os dois tipos de misturas asfálticas avaliadas não foi suficiente para sobrepor a dispersão nas emissões indiretamente causadas pela geometria das vias investigadas. Vale ainda salientar que, o RC é acrescido em torno de $20 \%$ para trabalhadores que tenham, previamente, o vício do tabagismo.

Dessa forma, o presente trabalho pode ser continuado a partir da investigação da dinâmica das emissões presentes em serviços de pavimentação, em meios urbanos altamente adensados, considerando o efeito do resfriamento da mistura asfáltica após a aplicação da mesma em campo. Outras variáveis presentes na composição dos materiais asfálticos (uso de aditivos para redução da temperatura de aplicação do material, valores elevados da porcentagem de CAP utilizados em misturas asfálticas, além de outros tipos de misturas asfálticas convencionais e mornas) podem ainda ser incorporadas durante as análises referentes ao nível de MPR gerado e ao RC durante a execução dessas atividades. 0 planejamento urbano das cidades pode ser aliado a investigação relativa as emissões em meios urbanos, considerando que regiões muito adensadas devem acentuar o efeito maléfico das emissões geradas em serviços de pavimentação (considerada como uma fonte passiva). 0 risco ocupacional ao trabalhador do setor de pavimentação também deve ser investigado com maior rigor em trabalhos futuros.

\section{REFERÊNCIAS}

Binet, S.; A. Pfohl-Leszkowicz; H. Brandt; M. Lafontaine e M. Castegnaro (2002) Bitumen Fumes: Review of Work on the Potential Risk to Workers and the Present Knowledge on its Origin. The Science of the Total Environ., v. 300, n. 1-3, p. 37-49. DOI: 10.1016/S0048-9697(02)00279-6.

Cavalcante, R. M.; C. A. Rocha; I. S. de Santiago e P. R. L. Thiers (2016) Influence of Urbanization on Air Quality Based on the Occurrence of Particle-Associated Polycyclic Aromatic Hydrocarbons in a Tropical Semiarid Area (Fortaleza-CE, Brazil). Air Qual Atmos Health., v.10, n. 4, p. 437-445. DOI 10.1007/s11869-016-0434-z.

Cavalcante, R. M.; F. W. Sousa; R. F. Nascimento; R. S. Silveira e G. S. S. Freire (2009) The Impact of Urbanization on Tropical Mangroves (Fortaleza, Brazil): Evidence from PAH Distribution in Sediments. Journal of Environmental Management, v. 91, n. 2, p. 328-335. DOI: 10.1016/j.jenvman.2009.08.020.

Cavalcante, R. M.; F. W. Sousa; R. F. Nascimento; E. R. Silveira e R. B. Viana (2011) Influence of Urban Activities on Polycyclic Aromatic Hydrocarbons in Precipitation: Distribution, Sources and Depositional Flux in a Developing Metropolis, Fortaleza, Brazil. Science of the Total Environment, v. 414, p. 287-292. DOI: 10.1016/j.scitotenv.2011.10.050.

Cheung K., N. Daher; W. Ka; M. M. Shafer; Z. Ning e J. J. Schauer (2011) Spatial and Temporal Variation of Chemical Composite Ion and Mass Closure of Ambient Coarse Particulate Matter (PM 10 - 2.5) in the Los Angeles Area. Atoms Environ; v. 45, n. 16, p. 2651-2662. DOI: 10.1016/j.atmosenv.2011.02.066.

Cole, P.; L. C. Green e T. L. Lash (1999) Lifestyle Determinants of Cancer among Danish Mastic Asphalt Workers. Regulatory Toxicology and Pharmacology 30, p. 1- 8. DOI: 10.1006/rtph.1999.1311.

Cravo, M. C. C. (2010) Estudos Relacionados aos Fumos de Asfalto. Conferência Proferida Durante o $3^{\circ}$ Workshop em SMS - Comissão de Asfalto do IBP. São Paulo/SP, Brasil. 
Cravo, M. C. C.; L. M. F. Leite; A. T. Martins; R. J. C. Monteiro; R. A. Azevedo; D. Bohrer e P. Nascimento (2010) Estudo Toxicológico dos CAPs Brasileiros. In: Encontro de Asfalto. Rio de Janeiro: Instituto Brasileiro de Petróleo, Gás e Biocombustíveis, Brasil.

Gasthauer, E.; M. Mazé; J. P. Marchand e J. Amouroux (2008) Characterization of Asphalt Fume Composition by GC/MS and Effect of Temperature. Fuel. v. 87, p. 1428-1434. DOI: 10.1016/j.fuel.2007.06.025.

Gaudefroy, V.; F. Deygout; V. Viranaiken; P. Le Coutaller; R. Paranhos e C. La Roche (2008) Laboratory Identification of Fumes During Manufacturing of Hydrocarbons Mixtures. In: International Society for Asphalt Pavements - ISAP, p. 278-286, França.

Guarnieri, M. e J. R. Balmes (2014) Outdoor Air Pollution and Asthma. The Lancet, v. 383, n. 9928, p. 3-9 May, p. $1581-1592$. DOI: $10.1016 / \mathrm{S} 0140-6736(14) 60617-6$.

Hamra, G. B.; N. Guha; A. Cohen; F. Laden; O. Raaschou-Nielsen; J. M. Samet.; P. Vineis; F. Forastiere; P. Saldiva; T. Yorifuji e D. Loomis (2014) Outdoor Particulate Matter Exposure and Lung Cancer: A Systematic Review and Meta-Analysis. Environmental Health Perspectives v. 122, p. 906-911. DOI: 10.1289/ehp.1408092.

Hansen, E. (1989) Cancer Mortality in the Asphalt Industry: A Ten Year Follow up of an Occupational Cohort. British Journal of Industrial Medicine, v. 46, p. 582-585.

Hicks, J. B. (1995) Asphalt Industry Cross-Sectional Exposure Assessment Study. Applied Occupational and Environmental Hygiene, v. 10, p. 840-848. DOI: 10.1080/1047322X.1995.10387699.

International Association for Research on Cancer - IARC (2009) A Case-control Study of Lung Cancer Nested in a Cohort of European Asphalt Workers. Final Report 1.

Lutes, C.C.; R. J. Thomas e R. Burnette (1994) Evaluation of Emissions from Paving Asphalts. Environmental Protection Agency EPA/600/SR-94/135. Washington, D.C.

McClean, M. D.; R. D. Rinehart; L. NGO; E. A. Eisen; K. T. Kelsey e R. F. Herrick (2004) Inhalation and Dermal Exposure among Asphalt Paving Workers. Ann. Occup. Hyg., v. 48, n. 8, p. 663-671. D0I: 10.1093/annhyg/meh062.

Motta, R. (2011) Estudos de Misturas Asfálticas Mornas em Revestimentos de Pavimentos para Redução de Emissão de Poluentes e de Consumo Energético. Tese de Doutorado. Escola Politécnica, Universidade de São Paulo (USP). DOI: 10.11606/T.3.2011-19072011-170629.

NIOSH - National Institute for Occupational Safety and Health (2000) Health Effects of Occupational Exposure to Asphalt: Hazard Review.

NR-15 - Norma Regulamentadora 15 (2008) Portaria no 3.214/78 do MTE. Manual Atlas, 62.ed. São Paulo.

NHO-08 - Norma de Higiene Ocupacional 08 (2009) Fundacentro. São Paulo/SP, Brasil.

Oke, T. R. (1988) Street Design and Urban Canopy Layer Climate. Energy and Building, v. 11, n. 1 a 3, p. 103-113. DOI: 10.1016/0378-7788(88)90026.

Olsson, A. H. et al. (2010) A Case-control Study of Lung Cancer Nested in a Cohort of European Asphalt Workers. Environ. Health Perspect. DOI:10.1289/ehp.0901800.

Organização Mundial da Saúde - OMS (2006) Air quality guidelines for particulate matter, ozone, nitrogen dioxide and sulfur dioxide. Geneva.

Partanen, T. e P. Boffetta (1994) Cancer risk in asphalt workers and roofers: Review and meta-analysis of epidemiologic studies. American Journal of Industrial Medicine, v. 26, n. 6, p. 712-740. DOI: 10.1002/ajim.4700260602.

Prowell, B. D. e G. C. Hurley (2007) Warm-mix Asphalt: Best Practices. Quality Improvement Series 125. Lanham: Nacional Asphalt Pavement Association (NAPA).

Raaschou-Nielsen, O. et al. (2013) Air pollution and Lung Cancer Incidence in 17 European Cohorts: Prospective Analyses from the European Study of Cohorts for Air Pollution Effects (ESCAPE). The Lancet Oncology, v. 14, p. 813 - 822 . DOI: 10.1016/S1470-2045(13)70279-1.

Rocha, C. A. (2014) Pressão Sonora, Sensação Térmica, Poluição do Ar e seus Riscos Associados como Indicadores da Qualidade Ambiental em Áreas Usadas para Esporte e Lazer. Trabalho de Conclusão de Curso (Graduação em Ciências Ambientais) Universidade Federal do Ceará (UFC), Fortaleza/CE.

Rocha, C. A.; F. W. Sousa; M. E. Zanella e R. M. Cavalcante (2017) Environmental Quality Assessment in Areas Used for Physical Activity and Recreation in a City Affected by Intense Urban Expansion (Fortaleza-CE, Brazil): Implications for Public Health Policy. Expo Health. DOI 10.1007/s12403-016-0230-x.

Seinfeld, J. H. e S. N. Pandis (1998) Atmospheric Chemistry and Physics from air pollution to climate change. New York. John Wiley and Sons, Incorporated. ISBN-13:978-0471720188.

Silva, I. B.; T. L. Silva; C. A. Rocha; R. M. Cavalcante e M. V. C. Silva (2016) Uso da Geoestatística na Avaliação da Distribuição de Material Particulado Respirável na Cidade de Fortaleza, Ceará. Revista Brasileira de Geografia Física. v. 9, n. 12, p. $334-344$. ISSN:1984-2295.

U.S. Environmental Protection Agency - US-EPA (1992) Guidelines for Exposure Assessment. U.S. Environmental Protection Agency, Risk Assessment Forum, Washington, DC, EPA/600/Z-92/001. Washington, D.C.

U.S. Environmental Protection Agency - US-EPA (1996) Guidance on Use of Modeled Results to Demonstrate Attainment of the Ozone NAAQS, EPA-454/B-95-007.

U.S. Environmental Protection Agency - US-EPA (1997) Exposure factors handbook; US Government Printing Office. EPA/600/889/043.

U.S. Environmental Protection Agency - US-EPA (2010) Air Pollution Standards. 
U.S. Environmental Protection Agency - US-EPA (2016) Climate Change Indicators in the United States. 4a Edição. EPA 430-R16-004. Acesso: www.epa.gov/climate-indicators.

Schreiner, C.A. (2011) Review of Mechanistic Studies Relevant to the Potential Carcinogenicity of Asphalts. Regulatory Toxicology and Pharmacology. v. 59, n. 2, p. 270-284. DOI: 10.1016/j.yrtph.2010.10.010.

Zanetti, M. C.; E. Santagata; S. Fiore; B. Ruffino; D. Dalmazzo e M. Lanotte (2016) Evaluation of Potential Gaseous Emissions of Asphalt Rubber Bituminous Mixtures. Proposal of a New Laboratory Test Procedure. Construction and Building Materials 113, p. 870-879. DOI: 10.1016/j.conbuildmat.2016.03.101. 